\title{
Numerical Analysis of the Compression Ratio's Influence, the Nature of the Fuel and the Injection Feed on the Cylinder Pressure
}

\section{Daniel Roméo Kamta Legue ${ }^{*}$, Marcel Obounou ${ }^{1}$, Ekobena Fouda Henri' ${ }^{1}$, Zacharie Merlin Ayissi², Mahamat Hassane Babikir ${ }^{1}$, Ivan Ehawe ${ }^{1}$}

\footnotetext{
${ }^{1}$ Department of Physics, Energy Laboratory, Electrical and Electronic Systems, University of Yaounde 1, Yaounde, Cameroon ${ }^{2}$ Faculty of Industrial Engineering, University of Douala, Douala, Cameroon

Email: *campusromo@yahoo.fr
}

How to cite this paper: Legue, D.R.K., Obounou, M., Henri, E.F., Ayissi, Z.M., Babikir, M.H. and Ehawe, I. (2019) Numerical Analysis of the Compression Ratio's Influence, the Nature of the Fuel and the Injection Feed on the Cylinder Pressure. Energy and Power Engineering, 11, 249-258.

https://doi.org/10.4236/epe.2019.116016

Received: May 16, 2019

Accepted: June 27, 2019

Published: June 30, 2019

Copyright $\odot 2019$ by author(s) and Scientific Research Publishing Inc. This work is licensed under the Creative Commons Attribution-NonCommercial International License (CC BY-NC 4.0). http://creativecommons.org/licenses/by-nc/4.0/ (c) (i) \& Open Access

\begin{abstract}
This article analyses numerically the simultaneous influence of the compression rate, fuel nature and the advanced injection of fuel on maximum cylinder pressure during the combustion phrase with the help of the Python Spyder calculation code. Indeed, several authors have shown that the combustion of biofuels which make it possible to compensate for fossil and exhaustible resources, presents a cylinder pressure higher by about 3.5\% compared to that of conventional diesel D100. This increase in pressure can be reduced by the means of controlling parameters making it possible to preserve the life of the engine and also reduce nitrogen oxides $\left(\mathrm{NO}_{\mathrm{x}}\right)$ and particular matter (PM). This article has two objectives which are: putting in place a numerical tool for the evaluation and simulation of thermal engines and the influence of control parameters on cylinder pressure. The single zone $0 \mathrm{D}$ combustion model which considers only the physical phenomena and considers the mixed fuel as a perfect gas is used. The fuel used is the Neem biofuel produced by Doctor Merlin Ayissi of the University of Douala and the D100 diesel fuel. The results are obtained from three fuel injection angles of $20^{\circ}, 13^{\circ}$ and $10^{\circ}$ before the TDC (Top Dead Centre) and three values of the engine compression rates of 15,20 and 25. The delay in combustion is characteristic of the fuel used as illustrated by the cetane number. The results show that the cylinder pressure increases with increasing compression rate and a very high advanced injection. It also shows that the pressure is high when diesel D100 is used instead of D100 biodiesel.
\end{abstract}

\section{Keywords}

Biofuel Compression Rate, Advanced Injection, Python 


\section{Introduction}

The engine sector for many years has been faced with the problems of fuel (fossil source which is exhaustible and also fluctuating prices) and pollution. With the objective of finding new fuels capable of replacing the existing sources, many researchers over the years have been pushed to the use of biofuels. The major problem of biofuels is generally the high pressure encountered during their combustion inside the cylinder. Almost all studies show an increase in $\mathrm{NO}_{\mathrm{x}}$ (nitrogen oxides) in post-combustion gases when biodiesels are used pure whatever the raw material [1]. The increase of $\mathrm{NO}_{\mathrm{x}}$ is very often due to the temperatures generated by the combustion of biodiesels. Heywood [1] proposes to inject a trickle of water into the cylinders to regulate these temperatures. This solution is quite laborious because it requires the incorporation of a water tank in the vehicle. The exhaust gas recirculation (EGR) proposed by Ballerini [1] significantly reduces nitrogen oxides $\left(\mathrm{NO}_{\mathrm{x}}\right)$ but the cylinder temperatures remain high. The burned gas recirculation (EGR) device makes it possible to reduce the cylinder pressure (temperatures) and consequently the $\mathrm{NO}_{\mathrm{x}}$ [1] [2] [3] [4] [5]. Another approach is one that recommends the use of water in the form of micro emulsion, emulsion or spray. The presence of well-managed residual moisture would reduce cylinder temperatures with a positive effect on $\mathrm{NO}_{\mathrm{x}}$ reduction. The addition of several fuels has been experimented by researchers to improve the performance of biodiesel [3]. It is, therefore, necessary to device strategies to considerably reduce the maximum attainable pressure during combustion. The ever-increasing world population is generating great quantities of waste that could serve as an energy source. The valorization of these waste will not only help reduce global warming caused by methane resulting from the degradation of these waste but also will provide a part solution to the world energy demand. To study diesel engines working under diverse control parameters, experiments can be replaced by numerical simulations which are advantageous as they reduce the time and cost linked to the construction of a prototype and apparatus for the experiments. The numerical simulation of the functioning of a diesel engine is based on mathematical equations describing the different physical processes taking place within the engine cycle. An elaboration of a mathematical model describing combustion in diesel engines gives a possibility of executing multiple optimization schemes and procedures; predict engine behaviour in varied conditions; and reduce expenditures of experimental research. The combustion model considered here is the 0D dimensional model [6] (thermodynamic and phenomenal models) integrated into Python. We go in this work through our model of enhanced combustion biodiesel as alternative fuel and also showed that we can play on the compression ratio and the injection advance to decrease the pressure (temperature) cylinder during combustion so to reduce the quantities of $\mathrm{NO}_{\mathrm{x}}$ in the engine.

\section{Modelling}

The single zone $0 \mathrm{D}$ model combustion model based on the first law of thermo- 
dynamics for a closed system is considered. Assumptions made are [7]:

- A homogenous fuel mixture considered a perfect gas

- Chemical equilibrium is attained during the combustion phase

- The initial combustion pressure is taken after compression

- Evolution of specific volume is a function of the crank angle

- The engine geometry is not considered

- The Woschni model of heat loss is considered

- The double phase Wiebe controls the fuel mass evolution

The auto inflammation delay is given by the Hardenberg and Hase [8]. The first law of thermodynamics is therefore written as:

$$
Q-W=U
$$

Considering the gas mixture as a perfect gas, hence, the relation [7]:

$$
P V=m R T
$$

With differential form:

$$
V \mathrm{~d} P+P \mathrm{~d} V=m R \mathrm{~d} T
$$

The internal energy of the perfect gas is a function of its temperature with differential form:

$$
\begin{gathered}
\mathrm{d} U=\mathrm{d}\left(m C_{v} T\right) \text { implying } \mathrm{d} U=m C_{v} \mathrm{~d} T+m T \mathrm{~d} C_{v} \text { giving } \\
\frac{R}{C_{v}}\left(\mathrm{~d} U-m T \mathrm{~d} C_{v}\right)=m R \mathrm{~d} T
\end{gathered}
$$

Equations (3) and (4) give:

$$
V \mathrm{~d} P+P \mathrm{~d} V=\frac{R}{C_{v}}\left(\mathrm{~d} U-m T \mathrm{~d} C_{v}\right)
$$

Using equation (3) gives:

$$
V \mathrm{~d} P+P \mathrm{~d} V=\frac{R}{C_{v}}\left(\mathrm{~d} U-m T \mathrm{~d} C_{v}\right)
$$

In Equation (6) $\mathrm{d} U=\frac{C_{v}}{R}(V \mathrm{~d} P+P \mathrm{~d} V)-m T \mathrm{~d} C_{v}$ and using the first principle applied to a closed system the following is obtained:

$$
\mathrm{d} Q_{n e t}-\mathrm{d} Q_{p}-P \mathrm{~d} V=\frac{C_{v}}{R}(V \mathrm{~d} P+P \mathrm{~d} V)-m T \mathrm{~d} C_{v}
$$

The classical hypothesis that the combustion chamber contains a homogenous mixture of a perfect gas at thermodynamic equilibrium is considered. When the valves are closed (i.e. compression and expansion phases) the speed at which the net heat is released equals energy flux liberated from burning the fuel after subtracting thermal loses. Dividing Equation (7) by $\mathrm{d} \theta$ : gives [9]

$$
\frac{\mathrm{d} Q_{n e t}}{\mathrm{~d} \theta}-\frac{\mathrm{d} Q_{p}}{\mathrm{~d} \theta}-P \frac{\mathrm{d} V}{\mathrm{~d} \theta}=\frac{C_{v}}{R}\left(V \frac{\mathrm{d} P}{\mathrm{~d} \theta}+P \frac{\mathrm{d} V}{\mathrm{~d} \theta}\right)-m T \frac{\mathrm{d} C_{v}}{\mathrm{~d} \theta}
$$

On the other hand: $\frac{R}{C_{v}}=\gamma-1$ and $C_{v}=\frac{R}{\gamma-1}$ differentiating with respect to 
$\theta$ gives:

$$
\begin{aligned}
& \frac{\mathrm{d} C_{v}}{\mathrm{~d} \theta}=-\frac{R}{(\gamma-1)^{2}} \frac{\mathrm{d} \gamma}{\mathrm{d} \theta} \text { where Equation (8) becomes: } \\
& \quad \frac{\mathrm{d} Q_{n e t}}{\mathrm{~d} \theta}-\frac{\mathrm{d} Q_{p}}{\mathrm{~d} \theta}-P \frac{\mathrm{d} V}{\mathrm{~d} \theta}=\frac{C_{v}}{R}\left(V \frac{\mathrm{d} P}{\mathrm{~d} \theta}+P \frac{\mathrm{d} V}{\mathrm{~d} \theta}\right)+\frac{m R T}{(\gamma-1)^{2}} \frac{\mathrm{d} \gamma}{\mathrm{d} \theta}
\end{aligned}
$$

making $\frac{\mathrm{d} P}{\mathrm{~d} \theta}$ the subject gives [5] [6] [7]:

$$
\frac{\mathrm{d} P}{\mathrm{~d} \theta}=\frac{\gamma-1}{V}\left(\frac{\mathrm{d} Q_{n e t}}{\mathrm{~d} \theta}-\frac{\mathrm{d} Q_{p}}{\mathrm{~d} \theta}\right)-\frac{\gamma P}{V} \frac{\mathrm{d} V}{\mathrm{~d} \theta}-\frac{P}{\gamma-1} \frac{\mathrm{d} \gamma}{\mathrm{d} \theta}
$$

The combustion chamber volume, $V$, is given by Equation (10) below which is a function of the engine geometric parameters [10]:

$$
V(\theta)=\frac{\pi D^{2} S}{8}\left(1-\cos (\theta)+\lambda-\sqrt{\lambda^{2}-\sin ^{2}(\theta)}+\frac{2}{C R-1}\right)
$$

The differential form of the volume is given by Equation (11) below:

$$
\frac{\mathrm{d} V(\theta)}{\mathrm{d} \theta}=\frac{\pi D^{2} S}{8}\left(1-\frac{\cos \theta}{\sqrt{\lambda^{2}-\sin ^{2} \theta}}\right) \sin \theta
$$

The parameters $\lambda, D, S, \theta$ and $C R$ in Equations (10) and (11) are respectively ratio of crank radius to Connecting rod length, cylinder bore, stroke, crank angle and compression rate. On the other hand, $\gamma$ is a function of temperature as given by the equation [11]:

$$
\gamma=1.458-1.628 \times 10^{-4} T+4.139 \times 10^{-8} T^{2}
$$

The term $Q_{p}$ characterising heat loss can be modeled by the formula:

$$
\frac{\mathrm{d} Q_{p}}{\mathrm{~d} \theta}=h_{c} A(\theta)\left(T-T_{p}\right) \frac{1}{\omega} \text { With } \omega=2 \pi N \quad \text { where } N \text { is the rotational speed of }
$$

the engine and $h_{c}$ the coefficient of heat transferred by convection given by the Woschni model below as a function of the characteristic engine geometry.

$$
\begin{gathered}
h_{c}=3.26 D^{-0.2} \times P^{0.8} \times T^{-0.55} \times W^{0.8} \text { with } W \text { as the piston speed expressed as: } \\
\qquad W(\theta)=2.28 \bar{U}_{p}+C_{1} \times \frac{V_{d} \times T_{a}}{P_{a} \times V_{a}}\left(P(\theta)-P_{m}\right)
\end{gathered}
$$

During the compression phase, $C_{1}=0$ while during the combustion and expansion phases:

$$
C_{1}=0.00324 \text { also } \bar{U}_{p}=\frac{N \times S}{30} \text {. The coefficient } C_{1} \text { depends on the phase }
$$
taking place in a diesel engine. The exchanged area $A(\theta)$ is given by the equation below:

$$
A(\theta)=\left(\pi \times \frac{D^{2}}{2}\right)+\pi \times D \times \frac{L}{2}\left(\lambda+1-\cos \theta-\sqrt{\lambda^{2}-\sin ^{2}(\theta)}\right)
$$

$Q_{n e t}$ represents the heat liberated during the combustion phase and can be modelled by the double phase Wiebe function, which describes the mass fraction of the fuel burnt during the combustion phase. This is written as [9]: 


$$
\begin{gathered}
x_{b}=1-\exp \left[-a\left(\frac{\theta-\theta_{0}}{\Delta \theta}\right)^{m+1}\right] \\
\frac{\mathrm{d} x_{b}}{\mathrm{~d} \theta}=\frac{1}{\Delta \theta} a_{v}\left(m_{v}+1\right)\left(\frac{\theta-\theta_{0}}{\Delta \theta}\right)^{m_{v}} \exp \left(-a_{v}\left(\frac{\theta-\theta_{0}}{\Delta \theta}\right)^{m_{v}+1}\right) \\
\frac{\mathrm{d} Q_{n e t}}{\mathrm{~d} \theta}=\frac{1}{\Delta \theta} m_{i n j} \cdot P C I a_{v}\left(m_{v}+1\right)\left(\frac{\theta-\theta_{0}}{\Delta \theta}\right)^{m_{v}} \exp \left(-a_{v}\left(\frac{\theta-\theta_{0}}{\Delta \theta}\right)^{m_{v}+1}\right) \\
x_{b}=1-\exp \left(-a_{v}\left(\frac{\theta-\theta_{0}}{\Delta \theta}\right)^{m_{v}+1}\right)
\end{gathered}
$$

The indices $a_{v}$ et $m_{v}$ are the Wiebe function parameters.

\section{Parametrization of the Model}

\section{a) Engine characteristics}

TheLISTER-PETTER-01005299-TS1 Series engine with characteristics listed below is simulated. (Table 1 )

b) Fuel characteristics (Table 2)

c) Wiebe parameters and heat loses

The model used is a simple phase Wiebe equation, the form factor $m_{v}=0.7$ and $a_{v}=5$ [9]. The heat loss model is the Woschni model in terms of the convection coefficient. The wall temperature is taken as $T_{p}=400 \mathrm{~K}$.

Table 1. Engine characteristics.

\begin{tabular}{cc}
\hline \multicolumn{2}{c}{ LISTER-PETTER-01005299-TS1 Série } \\
\hline General Information & 1 Cylinder with natural suction \\
Technical details & 4 stroke direct injection \\
\hline \multicolumn{1}{c}{ Cooling system: air cooled } \\
\hline Injection pressure (Bar) \\
Bore and Stroke (mm) \\
Connecting rod length (mm) \\
Cylinder capacity (cm $\left.{ }^{3}\right)$ & $95.3 / 88.9$ \\
Compression ratio & 165.3 \\
fuel injection timing BTDC & 630 \\
Nominal power & $15-20-25$ \\
Valve diameters Adm./Ech. (mm) & $13^{\circ}-15^{\circ}-20^{\circ}$ \\
Max lift of the valves (mm) & $4.5 \mathrm{KW}$ à 1500 trs $/$ min \\
Number of valves & $42 / 35$ \\
AOA/AOE & 10.61 \\
RFA/RFE & $256^{\circ} \mathrm{V} / 32^{\circ} \mathrm{V}$ after TDC \\
\hline
\end{tabular}


Table 2. Fuel characteristics.

\begin{tabular}{ccc}
\hline Fuel Properties & Biofuel (Neem, B100) & Diesel (D100) \\
\hline Density $\left(\mathrm{Kg} / \mathrm{m}^{3}\right)$ & 883.3 & 830 \\
Cetane Number & 56 & 39 \\
Calorific Value MJ/kg & 37.54 & 42.82 \\
$\% \mathrm{C}$ & 0.7791 & 86 \\
$\% \mathrm{H}$ & 0.1266 & 14 \\
$\% \mathrm{O}$ & 0.111 & Not defined \\
\hline
\end{tabular}

\section{Results and Discussion}

The numerical results are obtained by resolving the system of first order differential equations of temperature and cylinder pressure as a function of crank angle in Python. The pressure curves are illustrated in Figures 1-3 below.

The results above analyse the simultaneous influence of fuel nature, compression rate and advanced injection of fuel on peak cylinder pressure.

The Neem B100 and diesel D100 were used with injection advance crank angles of $13^{\circ}, 15^{\circ}$ and $20^{\circ}$ before TDC and compression ratios of 15,20 and 25. The injection advance is a determining factor for the peak pressure. The injection advance of the fuel could help predict the quantity of fuel burnt before the TDC (using the Wiebe function) the earlier the fuel is injected, the more the pressure peak approaches the TDC. Attaining peak pressure near the TDC should be avoided because it has an enormous influence on the engine performance parameters and engine components [9] and [10].

Figure 1 and Figure 3 shows that using diesel D100 and Neem B100, the peak pressure occurs around $370^{\circ}$ and $365^{\circ}$ when injection advances of $13^{\circ}$ and $20^{\circ}$ crank angles are used respectively before the TDC. This shows that an injection advance of $13^{\circ} \mathrm{V}$ is the best compared to $15^{\circ}$ and $20^{\circ}$. Results show that the peak pressure increases when the injection advance is big. An increase of about 10 bars in the peak pressure is observed when the injection advance changes from $13^{\circ} \mathrm{V}$ to $20^{\circ} \mathrm{V}$ [9] and [12]. It could be drawn from these results that the problem of high pressure encountered in diesel engines when using bio fuels could be resolved by varying injection advance. Indeed, the moment of fuel injection is a very important parameter in the compression engine. The thermodynamic state of the air that is preheated by the compression phase depends on the position of the piston in the cylinder. Ignition delay is a function of the state of the air in the cylinder; it becomes obvious that injecting fuel rather than expected will not find air in its standard state; which modifies the entire combustion phase. In addition, the majority of the fuel is generally burned during the pre-mixing phase which causes a maximum pressure around the TDC [13].

The graphs have the same shape when varying the compression ratio in each case. It is seen that the higher the compression ratio the more the maximum pressure is elevated; this means that the initial combustion pressure which 


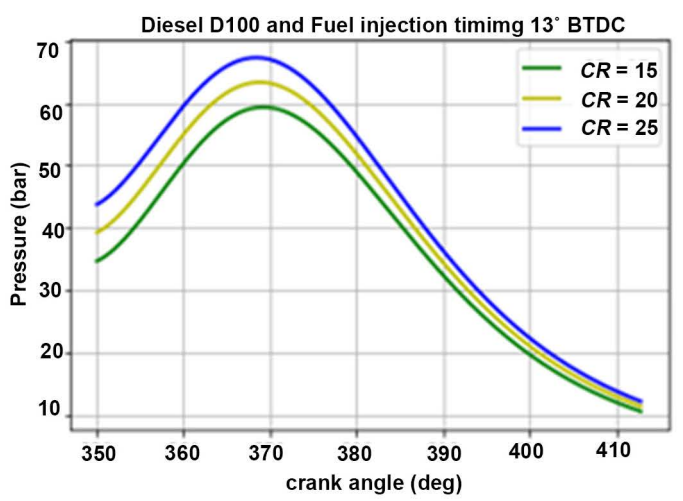

(a)

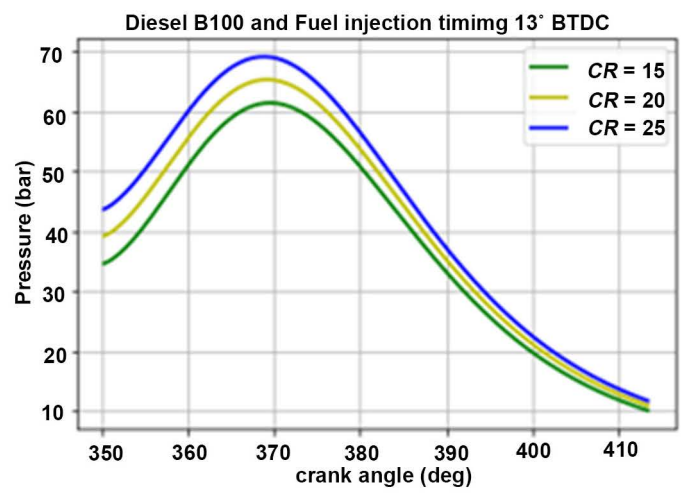

(b)

Figure 1. Cylinder pressure for fuel injection timing $13^{\circ}$ BTDC.

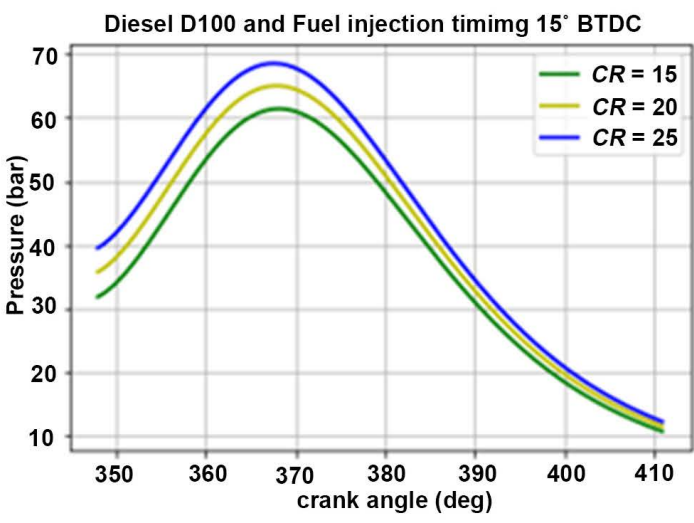

(a)

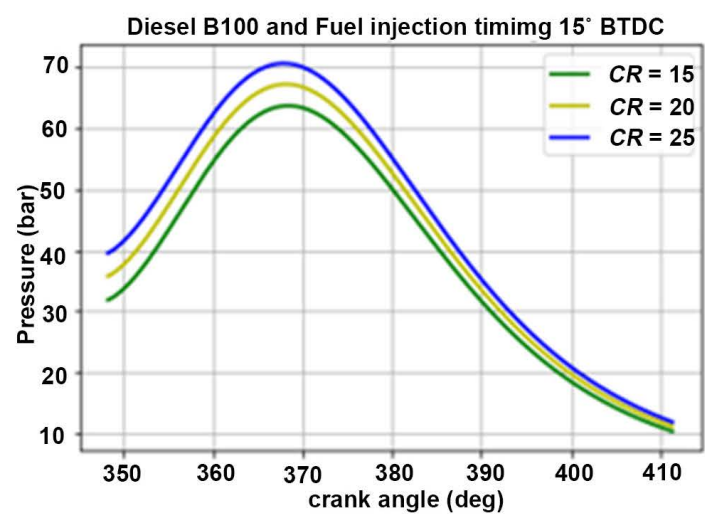

(b)

Figure 2. Cylinder pressure for fuel injection timing $15^{\circ}$ BTDC.

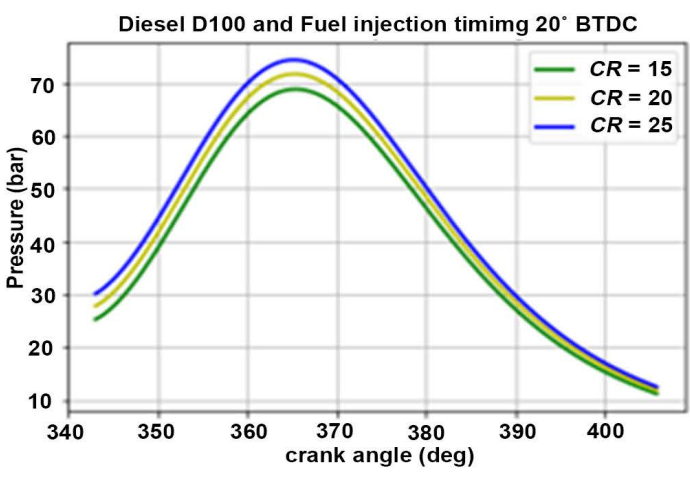

(a)

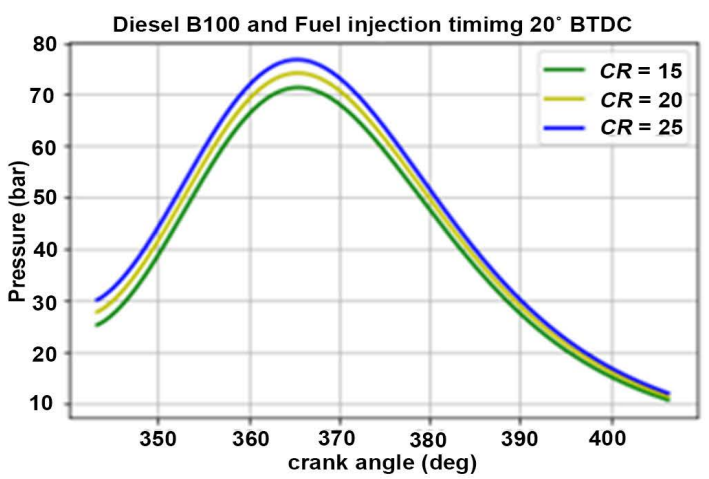

(b)

Figure 3. Cylinder pressure for fuel injection timing $20^{\circ}$ BTDC.

represent the end of the compression phase depends on the compression ratio in the cylinder.

The peak pressure when using the Neem biofuel is more important than that from conventional diesel D100 $\left(\mathrm{C}_{10.65} \mathrm{H}_{20.8}\right)$ due to the presence of oxygen in the chemical composition of the biofuel. This means the combustion of B100 
$\left(\mathrm{C}_{22.36} \mathrm{H}_{43.64} \mathrm{O}_{2}\right)$ occurs under good conditions as compared to conventional diesel D100. This same remark was made by L. Tabaret [14] and others. The cetane number for B100 is very high compared to that of D100; which signifies the ability of auto inflammation of a fuel.

The validation of the model is based on the experimental carried out by Dr. Ayissi Merlin [15] and [16]. [16] shows advancing fuel injection timing increases the peak cylinder pressure for D100 and B100. [15] shows the peak cylinder pressure of biodiesel has 89.9 while the peak cylinder pressure of diesel D100 has 85.9 bars, the cylinder pressure is $44 \%$ higher during the use of biodiesel B100 compared to $42 \%$ for use of conventional diesel D 100 .

\section{Conclusion}

In this article, it was a question of show that the problem of high temperature or high pressure encountered during the combustion of biofuels in diesel engines can be mitigated by the injection advance and the compression ratio of the engine. Equally, it was a question of showing that the emission of pollutants due to the combustion of fossil fuels can be satisfied by the use of biofuels. This study showed that the combustion of biodiesel takes place in better combustion than that of conventional diesel. Indeed, the Neem biodiesel presented a more important peak than the conventional diesel D100. In order to reduce the emission of $\mathrm{NO}_{\mathrm{x}}$ and particulate matter (PM), we will use the present model to reduce the quantities of $\mathrm{NO}_{\mathrm{x}}$ that strongly depends on the temperature.

\section{Acknowledgements}

We particularly thank the G.C.C team for always encouraging us in combustion and simulation aspects. We equally thank our team members in the Energy, Electric and Electronic Systems of the University of Yaoundé 1 for welcoming and assisting us in our research.

\section{Conflicts of Interest}

The authors declare no conflicts of interest regarding the publication of this paper.

\section{References}

[1] Mohamed, F., Al-Dawody and Bhatti, S.K. (2014) Experimental and Computational Investigation for Combustion, Performance and Emission Parameters of a Diesel Engine Fueled with Soybean Biodiesel-Diesel Blends. Energy Procedia, 52, 421-430. https://doi.org/10.1016/j.egypro.2014.07.094

[2] Heywood, J.B. (1988) Internal Combustion Engines Fundamentals. McGraw Hill, Pennsylvania.

[3] Labeckas, G. and Slavinskas, S. (2006) The Effect of Rapeseed Oil Methyl Ester on Direct Injection Diesel Engine Performance and Exhaust Emissions. Energy Conversion and Management, 47, 1954-1967.

https://doi.org/10.1016/j.enconman.2005.09.003 
[4] Gokalp, B., Buyukkaya, E. and Soyhan, H.S. (2011) Performance and Emissions of a Diesel Tractor Engine Fueled with Marine Diesel and Soybean Methyl Ester. International Journal of Biomass and Bioenergy, 35, 3575-3583. https://doi.org/10.1016/j.biombioe.2011.05.015

[5] Buyukkaya, E. (2010) Effects of Biodiesel on a DI Diesel Engine Performance, Emission and Combustion Characteristics. Fuel, 99, 3099-3105. https://doi.org/10.1016/j.fuel.2010.05.034

[6] Samanta, A., Das, S. and Roy, P.C. (2016) Performance Analysis of a Biogas Engine. International Journal of Research in Engineering and Technology, 5, 67-71. https://doi.org/10.15623/ijret.2016.0513012

[7] Samanta, A., Das, S. and Roy, P.C. (2016) Modeling of Compression Engines Using Biodiesel as Fuel. International Journal of Research in Engineering and Technology, 5, 72-77. https://doi.org/10.15623/ijret.2016.0513013

[8] Ngayihi Abbe, C.V. (2013) Simulation of a DI Diesel Engine Performance Fuelled on Biodiesel Using a Semi-Empirical 0D Model. Energy and Power Engineering, 5, 596-603. https://doi.org/10.4236/epe.2013.510066

[9] Grondin, O. (2004) Modélisation du moteur à allumage par compression dans la perspective du contrôle et du diagnostic.

[10] Aklouche, F.Z. (2018) Etude caractéristique et développement de la combustion des moteurs Diesel en mode Dual-Fuel: Optimisation de l'injection du combustible pilote. Thermique, Ecole nationale supérieure Mines-Télécom Atlantique.

[11] Kerihuel, A., Senthil, K.M., Bellettre, J. and Tazerout, M. (2005) Use of Animal Fats as CI Engine Fuel by Making Stable Emulsions with Water and Methanol. Fuel, 84, 1713-1716.

[12] Sun, L., Liu, Y.F., Zeng, K., Yang, R. and Hang, Z.H. (2015) Combustion Performance and Stability of a Dual-Fuel Diesel-Natural-Gas Engine. Proceeding of Institution of Mechanical Engineering, Part D: Journal of Automobile Engineering, 229, 235-246. https://doi.org/10.1177/0954407014537814

[13] Raheman, H. and Ghadge, S. (2008) Performance of Diesel Engine with Biodiesel at Varying Compression Ratio and Ignition Timing. Fuel, 87, 2659-2666. https://doi.org/10.1016/j.fuel.2008.03.006

[14] Tarabet, L. (2012) Etude de la combustion d'un biocarburant innovant dans les moteurs à combustion interne de véhicules. Thèse, Ecole des Mines de Nantes, Nantes.

[15] Merlin, A.Z., et al. (2015) Development and Experimental Investigation of a Biodiesel from a Nonedible Woody Plant: The Neem. Renewable and Sustainable Energy Reviews, 52, 201-208.

[16] Rostami, S. (2014) Effect of the Injection Timing on the Performance of a Diesel Engine Using Diesel-Biodiesel Blends. International Journal of Automotive and Mechanical Engineering, 10, 1945-1958.

https://doi.org/10.15282/ijame.10.2014.12.0163 


\section{Nomenclature}

$\theta$ : cranck angle $\left({ }^{\circ} \mathrm{CA}\right)$

$\Delta \theta$ : total combustion duration $\left({ }^{\circ} \mathrm{CA}\right)$

$\theta_{0}$ : Start of combustion $\left({ }^{\circ} \mathrm{CA}\right)$

$X$ : burnt mass fraction

$W$ : Work done (KJ)

$U$ : Internal energy

$C R$ : Compression ratio

$c_{v}$ : Specific heat at constant volume

$h_{c}$ : heat transfer coefficient $\left(\mathrm{W} \cdot \mathrm{m}^{-2} \cdot \mathrm{K}^{-1}\right)$

M: Masse (Kg)

$R:$ Gas constant

$Q$ : Heat transfer (KJ)

$V$ : Volume $\left(\mathrm{m}^{3}\right)$

$P$ : Pressure (Bar)

T: Temperature (K)

$A(\theta)$ : Area exposed to heat transfer $\left(\mathrm{m}^{2}\right)$

$D$ : Cylinder bore (m)

$S$ : Stroke (m)

$N$ : rotational speed of the engine

$\omega:$ Angular velocity ( $\mathrm{rad} / \mathrm{s})$

$\bar{U}_{p}:$ Mean piston speed

BTDC: Before Top Dead Centre 